\title{
Calcification of Superficial Nerves in Leprosy
}

\author{
G. C. PANT, M.D., D.M.R.E. \\ V. N. SEHGAL, M.D. \\ From the Department of Radiology and Section of Dermatology, Department of Medicine, \\ College of Medical Sciences, Banaras Hindu University, Varanasi-5 (India)
}

$M$. leprae has got a special predilection for the superficial nerves. The pattern of histopathological changes which ultimately emerge as a result of its lodgement in the nerve tissue has been described by some workers ${ }^{6}{ }^{13}$. No mention has been made about the calcification of nerves in leprosy even in the comprehensive text-book by Cochrane and Davey ${ }^{3}$. However, some workers $^{12457891011} 121516$ have reported stray cases of its occurrence in neuritic leprosy. The study on the radiological evidence of calcification of nerves as such has not been thoroughly undertaken.

The present study was carried out to find the radiological evidence of macroscopic calcification and its probable relationship to its prognosis.

\section{MATERIALS AND METHODS}

Fifty patients, comprising 35 with tuberculoid, 10 with neuritic and 5 with leprotic nerve abscesses formed the subject for the study. These patients were collected from the 'Dermatologic' section of Sir Sunder Lal Hospital, Banaras Hindu University. The diagnosis in each case was made on clinical grounds. The involvement of the ulnar nerve at the elbow region in the form of thickening and tenderness or the formation of nerve abscess was the common denominator in all cases. All the patients were invariably on therapy with Diamino-diphenylsulphone sometime or another.

Radiological antero-posterior view of the affected elbow region was taken considering the following factors as tabulated below:-

\begin{tabular}{cccc}
\hline K.V. & M.A.S. & F.F.D. & Screen film \\
\hline 40 & 8 & $36^{\prime \prime}$ & Yes \\
\hline
\end{tabular}

The above factors were taken into account for the X-rays of soft tissue, though the nonscreened films are claimed to be ideal but in our results we found comparable contrast with the screened films to the best of our satisfaction. As a standard, small focus was chosen for radiographs of the series.

\section{OBSERVATIONS}

No evidence of radiological calcification was seen in any of our patients (Figs. 1 and 2). However, in 5 patients irregular, increased soft tissue shadow was seen in radiographs at the level of lower one third of the humerus in the region of the ulnar nerve on the medial side (Fig. 3). The patients with leprotic nerve abscesses were confirmed at operation as reported earlier by one of the authors ${ }^{14}$.

\section{DISCUSSION}

Calcification of superficial nerves in leprosy is extremely rare and has been infrequently reported. It has been observed exclusively in the neuritic variety by most of the workers $^{12457891011121516}$. Some workers ${ }^{251013}$ found oval blobs of calcification conforming to the calcification of old nerve abscesses. However, Trapnell ${ }^{16}$ and Ramanujam and Ramu ${ }^{12}$ have reported one case each where calcification was seen radiologically in the nerve as such. 


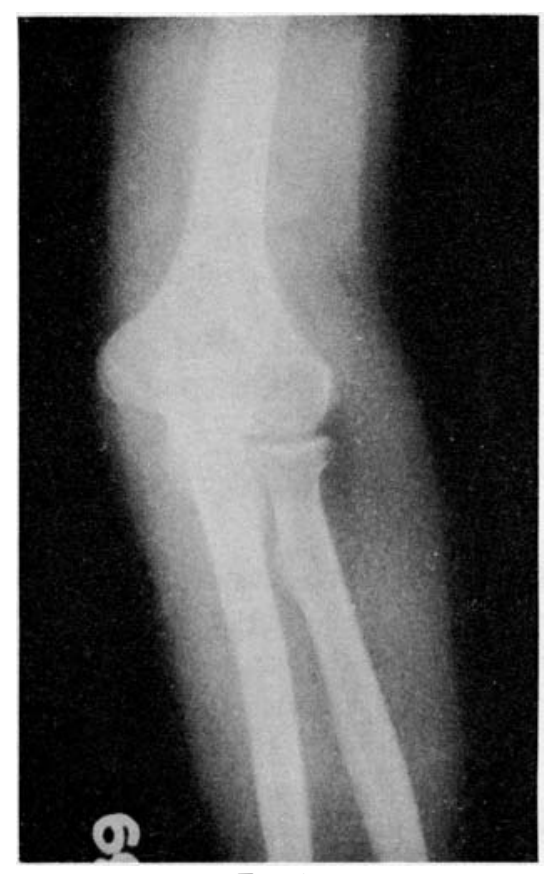

FIG 1

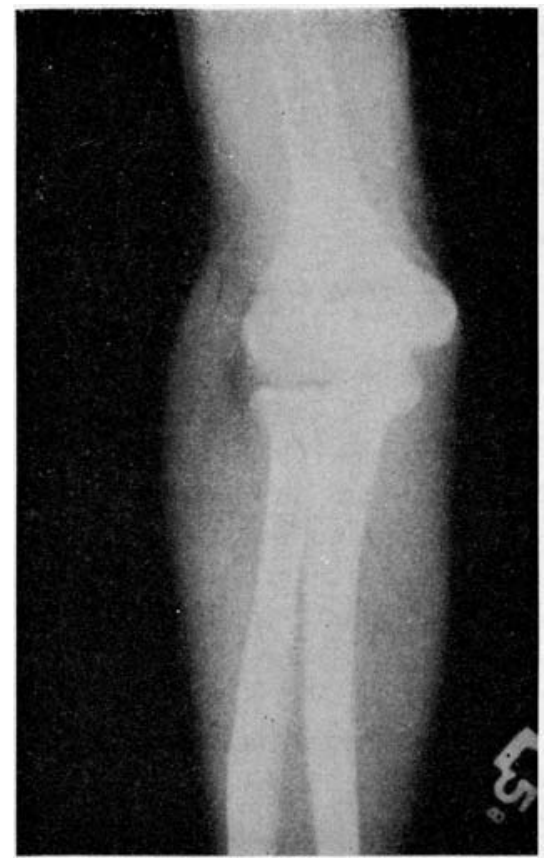

FIG 2

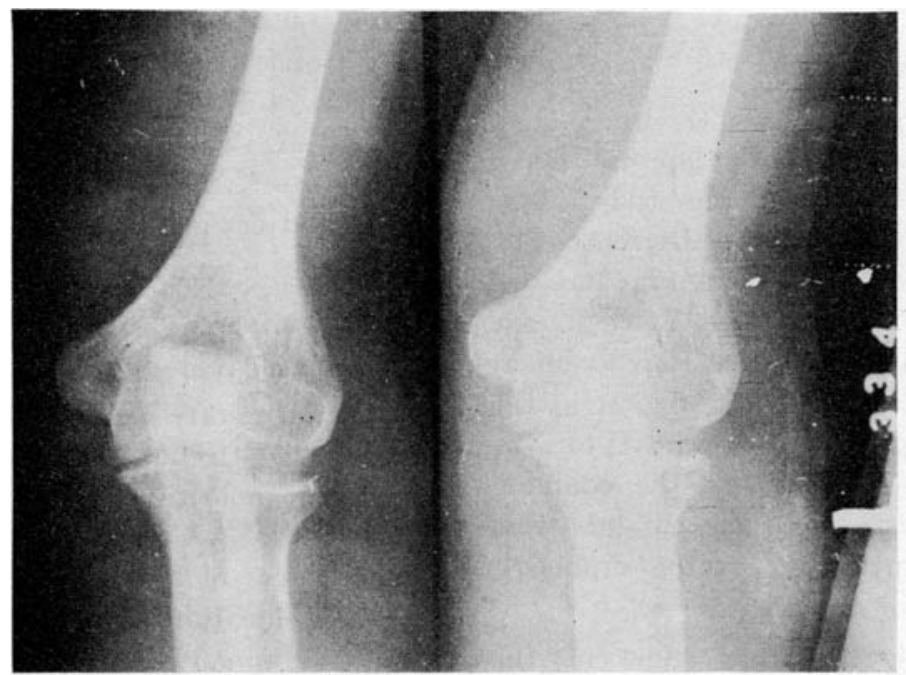

FIG 3 
In our series, on the other hand, comprising different stages of the disease no macroscopic radiological calcification was seen including those of nerve abscesses which are reported to be extremely rare ${ }^{14}$. Our observations, therefore, do not support the findings of the earlier workers.

No adequate explanation for the absence of calcification in our series could be given. It seems plausible that the therapy with Diaminodiphenyl-sulphone has changed the pattern of natural course of the disease resulting in lesser degenerative changes in the nerve tissue, thus limiting the chances of deposition of calcium. The marked degenerative changes in the nerve are supposed to be the pre-requisite for dystrophic calcification.

It is unlikely that calcification of nerves in leprosy will help in the evaluation of its prognosis.

\section{SUMMARY}

Fifty patients in different stages of leprosy were studied for the evidence of macroscopic radiological calcification in superficial nerves. No calcification was seen in any of our patients.

\section{ACKNOWLEDGEMENTS}

The authors avail themselves of this opportunity to thank Dr. A. K. Bhattacharyya, Prof essor and Head of Department of Radiology, and Dr. S. P. Ganguly, Reader in Radiology, College of Medical Sciences, for providing the facilities to conduct this study.

\section{REFERENCES}

1. campos, N. s. Calcification of nerves in leprosy. Abstracted in Int. J. Lepr. (1947), 15, 362.

2. CAmpos, J. м. C. Calcification of nerves in leprosy. Abstracted in Int. J. Lepr. (1947), 15, 362.

3. Cochrane, R. G. and DAVEy, T. F. Leprosy in Theory and Practice. Bristol, John Wright and Sons Ltd. 2nd edition (1964).

4. contreras, F., terencio, J. and tarabini, J. Calcification of cubital nerve. Abstracted in Int. J. Lepr. (1961), 29, 250.

5. FLoch, H. and Destombes, P. On a Calcified nodule of a leprous cubital nerve in Leprosy-Neuritis and its sequelae. Published by Leonard Wood Memorial, (1960) 29.

6. KHANOLKAR, v. R. in Leprosy in Theory and Practice by Cochrane, R. G. and Davey, T. F. Bristol, John Wright and Sons Ltd. 2nd edition, (1964) $125-151$.

7. LIE, H. P. Curability of Leprosy. Int. .J. Lepr. (1935), 3, 14.

8. merestang and combenale. Cited by Nolasco (10).

9. Mitsuda, K. Calcification of neural tissue (neural leprosy) in Atlas of Leprosy. Chotokai Foundation Okoyama, Japan (1952), 10.

10. Nolasco, J. O. Calcification and Osteoid changes in nerve in Leprosy. Int. J. Lepr. (1936), 4, 25-27.

11. ota and sato. Cited by Nolasco (10).

12. ramanuJam, $\mathrm{K}$. and Ramu, G. Calcification of peripheral nerve trunk in leprosy report of a case. Lep. in India (1966), 38, $185-190$.

13. SAIKAWA, K. The histological studies of the peripheral nerves in various clinical phases of leprosy in Leprosy-Neuritis and sequelae. Published by Leonard Wood Memorial (1960), 29.

14. Sehgal, v. N., TULI, S. M. and DUBE, B. Leprotic nerve abscesses in Northern India. Int. .J. Lepr. (1967), 35, 601-64.

15. Shiota, h. Cited by Nolasco (10).

16. Trapneli, D. H. Calcification of nerves in lepresy Brit. J. Radiol. (1965), 38, 796-797. 